Cahiers de la recherche sur les droits

Cahiers

Fur les Droits fondamentaux

6 | 2008

Pouvoirs exceptionnels et droits fondamentaux

Droit et pluralisme, Lauréline Fontaine (dir.)

\title{
OpenEdition
}

1 Journals

Édition électronique

URL : https://journals.openedition.org/crdf/6948

DOI : $10.4000 /$ crdf.6948

ISSN : 2264-1246

Éditeur

Presses universitaires de Caen

Édition imprimée

Date de publication : 31 décembre 2008

Pagination : 187

ISBN : 978-2-84133-259-5

ISSN : $1634-8842$

Référence électronique

"Droit et pluralisme, Lauréline Fontaine (dir.) », Cahiers de la recherche sur les droits fondamentaux [En

ligne], 6 | 2008, mis en ligne le 11 décembre 2020, consulté le 14 novembre 2022. URL : http://

journals.openedition.org/crdf/6948; DOI : https://doi.org/10.4000/crdf.6948 


\title{
Ouvrages reçus
}

\section{Droit et pluralisme}

\author{
Lauréline Fontaine (dir.)
}

Bruxelles, Bruylant (Droit et justice ; 76), 2007

ISBN : 978-2-8027-2485-8; 398 p.; $60 €$

Le pluralisme est une notion empruntée par le droit à la pensée politique, historique et philosophique. Comme fondement reconnu de la démocratie, l'exigence de pluralisme a des conséquences juridiques importantes, dont beaucoup sont encore toutefois à découvrir. Plusieurs thèmes sont ainsi envisagés : les sources du pluralisme, comme théorie et comme phénomène; le traitement jurisprudentiel du pluralisme; les théories juridiques liées au pluralisme; le pluralisme comme principe d'action et enfin les contradictions de l'exigence nécessaire de pluralisme. Les contributions de cet ouvrage concernent les deux approches du pluralisme qui ne semblent pas nécessairement séparables, à savoir le pluralisme des droits comme condition de la démocratie, tel que le détermine notamment la Cour européenne des droits de l'homme, et le pluralisme juridique comme pluralisme des normes. Toutes ces questions sont ainsi organisées autour de trois angles d'approche: (1) les origines du pluralisme, (2) les significations du pluralisme et (3) le pluralisme saisi par le juge.

Ont contribué à cet ouvrage : Jean-François Akandji-Kombé, Marie-Anne Cohendet, Françoise Dreyfus, Lauréline Fontaine, Geneviève Koubi, Jean-Manuel Larralde, Philippe Lauvaux, Marie-Laure Mathieu-Izorche, Carlos Miguel Pimentel, Marie-Joëlle Redor, André Reszler, Jean-Marc Sorel, Frédéric Sudre, Guillaume Tusseau.

\section{La citoyenneté européenne}

\section{Stéphane Leclerc, Jean-François Akandji-Kombé (dir.) Bruxelles, Bruylant (Rencontres européennes; 6), 2006}

ISBN : 978-2-8027-2274-8; 184 p.; $45 €$

Lors de la signature du traité de Rome, l'objectif fondamental des États membres était avant tout économique. Toutefois, au fur et à mesure de l'évolution de la construction communautaire, il est apparu nécessaire, voire même indispensable, de rapprocher l'Europe de ses citoyens. C'est pourquoi le traité de Maastricht de 1992 insère dans le traité de Rome des dispositions instaurant la «Citoyenneté de l'Union». Ainsi, tout ressortissant d'un État membre de l'Union européenne est à la fois citoyen de son pays et citoyen de l'Union européenne. Cette citoyenneté de complémentarité se situe aujourd'hui indubitablement au cœur du projet européen et s'inscrit ainsi de fait parmi les fondements de l'Union européenne.

L'objectif de cet ouvrage, destiné aussi bien aux universitaires qu'aux professionnels, est de faire le point sur la citoyenneté européenne dans sa dimension historique et juridique, mais également dans ses aspects politiques et sociologiques, et d'en tracer certaines perspectives d'avenir. 